\title{
Reseña
}

\section{Ética antioqueña a oscuras}

DOI: http://dx.doi.org/10.18566/comunica.n42.a0

Fecha de recepción: 27 de febrero de 2020

Fecha de aceptación: 5 de junio de 2020

\section{Introducción}

El "Medellín a oscuras" del título del libro hace referencia a los años más convulsos de la confrontación entre el Cártel de Medellín y el Estado colombiano, momento en que el terrorismo eclipsó a una sociedad que no estaba preparada para la magnitud de la violencia desatada y que, a pesar de no haberse rendido, salió mal librada del espectáculo dantesco que presenció toda una generación. La unidad temática del narcotráfico y sus afectaciones en la infraestructura social, política y cultural de Medellín constituye el hilo conductor de una narrativa que, a través de distintas voces protagonistas de la época, reconstruye por cuadros lo que significó convivir en medio del miedo y la zozobra; un relato testimonial desde el poder, el periodismo y la academia.

En cuanto al tema de la ética, la pregunta de si el narcotráfico trastocó los modos de un tipo de comportamiento moral antioqueño o de si se trató de una huella presente como herencia del contrabando resulta significativa para ver el fenómeno en conjunto y no únicamente como el accionar de un grupo de vándalos nacidos por generación espontánea. Esta reflexión de Ana Cristina Aristizábal cobra vigencia en un contexto en que las narrativas de los medios de comunicación y una cierta condescendencia favorable a la figura de Pablo Escobar han colonizado los imaginarios de nuevas generaciones desconectadas de los acontecimientos de los años referenciados (19881993). Por otro lado, esa mal llamada "cultura mafiosa" sigue vigente en expresiones de la política en Antioquia y es validada por una buena cantidad de personas que aún ven en la violencia una salida a los problemas más agudos que enfrenta la sociedad colombiana.

La profesora Aristizábal está acompañada por estas preguntas, debido a que los años que describe en el texto fueron aquellos en los que ejercía la profesión como reportera en un noticiero de televisión nacional y (desde donde presenció la barbarie que ahora recoge en medio de oleadas de recuerdos sobre bombas, atentados, tiroteos y asesinatos de policías, jóvenes y figuras políticas de primer orden). En su momento, no había tiempo para pensar y reflexionar sobre lo que acontecía desde el periodismo, porque 
cada día era una nueva batalla contra el tiempo entre hechos simultáneos donde primaba el del mayor número de muertos. Así, muchas historias fueron invisibles y quedaron sepultadas debajo de aquella "tonelada de sucesos". Colombia estaba perdiendo una batalla contra sí misma, diezmada por un poder al que vio crecer, pero que no quiso ver y, cuando prendió alarmas, era ya, como lo describe en su libro el escritor Guillermo Cardona, una bestia desatada (2007).

Por eso Aristizábal, sin abandonar su olfato periodístico, ahora en oficios académicos, se retrotrae sobre lo que debió dejar en reposo durante años, tal vez impactada aún por los rostros del dolor y la muerte, para adentrarse en los archivos y recoger uno a uno los bombazos que retumbaron en su pecho durante años. Esta es la forma que encontró para soltar por fin ese pasado que atormentaba sus recuerdos al volver sobre los días en que tal vez hubiera preferido leer a los clásicos y vivir guerras imaginarias para no tener que soportar las propias. Su encierro de tardes enteras en el archivo de El Colombiano es un volumen periodístico invaluable sobre la cronología del terror que fracturó a Medellín.

En el libro hay una serie de entrevistas con personajes reconocidos, como los alcaldes de la época (Juan Gómez Martínez, Omar Flórez Vélez y Luis Alfredo Ramos Botero), con quienes Aristizábal hace un recuento más de la intimad del poder frente al denominado narcoterrorismo con anécdotas que resultarán inverosímiles, como aquella donde Juan Gómez es protagonista de un tiroteo en su casa: él mismo, arma en mano, termina enfrentado a los sicarios de Escobar. Aquel fue el momento en que la política debió voltear su mirada a las periferias de la ciudad, invisibles por años, pero donde se libraba la guerra urbana que hizo tristemente célebre a Medellín, la ciudad más peligrosa del mundo junto a Beirut, capital del Líbano que estaba en guerra civil desde 1975.

Este fue sin duda un fenómeno que había que comprender; por eso hay una entrevista con Alonso Salazar, escritor y periodista, quien por esos años, desde la Corporación Región, se dedicó a comprender la dinámica del conflicto entre los jóvenes de los barrios periféricos, más conocidos por el estigma mediático de las comunas; inexplorados e impenetrables territorios que logró cruzar para conversar con los protagonistas de una historia que puso en jaque la vida de estas periferias y, desde allí, a la ciudad misma. De estas experiencias nació su libro No nacimos pa' semilla (1990), la semblanza de un horizonte distinto al que en algún momento plasmó Francisco Antonio Cano (1913).

Todo este cúmulo de historias y acontecimientos tienen un encadenamiento social, político, económico y cultural que académicos como Gustavo Duncan han logrado desentramar, cartografiar y nombrar. Ya no se trata de ver solo 
la estructura local de un negocio, sino los hilos que conectan el problema de orden nacional y su infraestructura internacional. El crimen organizado alrededor de las rentas del narcotráfico, vinculado con mafias de todo tipo, hace de este problema una industria multinacional que explica la captura de todo orden social, político y de clase social.

Como las salas de redacción, además de amenazadas, ardían por el calor de los acontecimientos, el testimonio de Carlos Alberto Giraldo (Capeto) es fundamental para entender cómo se vivía el día a día de la noticia, cómo se afrontaba desde el periodismo un episodio prolongado que no parecía tener fin y al que periodísticamente se le iban agotando los tratamientos para aprehenderlo. Algo de esto ya lo habíamos leído en Las llaves del periódico (2009) de Carlos Mario Correa y Marco Antonio Mejía, de quienes obtuvimos el testimonio vivo de lo que significa sobrevivir a la barbarie atrincherado detrás de la noticia. Con Capeto retomamos una lectura necesaria para estos tiempos en que aquel episodio parece haber pervivido, agazapado entre otros alias y denominaciones.

Considero que esta obra es necesaria entre nuevas generaciones de estudiantes de periodismo y, sobre todo, en cátedras o charlas estudiantiles de los colegios de la ciudad de Medellín para evidenciar lo que significó el narcotráfico y esa doble moral que validó, y que aún justifica, la connivencia entre lo legal y lo ilegal. El recorrido que evidencia el texto desde los años 50, con el contrabando, hasta el auge del narcotráfico en las décadas de los 70 y 80 deja claro que en Colombia se aceptó esta connivencia desde las más altas esferas y se justificó su accionar delictivo.

En el texto, Ana Cristina Aristizábal rescata el lenguaje periodístico como un método investigativo de carácter mixto, enriquecido con narrativas analíticas que aportan a la contextualización, a pesar de su advertencia preliminar de que no se está ante un texto estrictamente académico. Sin embargo, su estructura basada en testimonios, la revisión bibliográfica y el análisis social logran un contenido que rescata la importancia, en términos de memoria colectiva, de un fenómeno que aún muchos no comprenden y que, por el uso que se ha hecho por parte de los medios de comunicación, ha devenido en historias de héroes y villanos.

El libro comienza con reflexiones nacidas de otras fuentes bibliográficas de un gran valor, como el estudio de Gerard Martin Tragedia y resurrección. Mafia, ciudad y Estado 1975-2012, donde se registran las múltiples relaciones a las que se hace referencia cuando se describe el narcotráfico. Obras como estas corresponden a clásicos del tema, con lo que se hace una ajustada comprensión histórica y actual del fenómeno. Sin duda, el gran valor de 
este trabajo es el uso de las fuentes de prensa, con las que se recuperan los hechos que resaltan toda la magnitud del momento vivido.

Es una obra necesaria para este momento del país en que se cree que el narcotráfico y su imposición de valores está superado y que la figura de Pablo Escobar ya no es un referente. Tanto el narcotráfico como Escobar continúan vivos en el imaginario colectivo y tenemos de esto una distorsión mediatizada que los ha convertido en una suerte de héroes o "males necesarios" de una época que la autora logra deslucir con su indagación periodística. Su fortaleza está en lograr ordenar sistemáticamente aquellos acontecimientos que han entrado en el olvido y a los que, por tanto, no se les presta mayor atención, además de poner a hablar de nuevo a aquellos personajes a quienes les tocó enfrentar el fenómeno de la violencia asociado al narcotráfico. Estos testimonios, treinta años después, dejan en evidencia los vacíos que la autora quiere resaltar, como la actuación de tres de los alcaldes del momento, más ocupados en "apagar los incendios" que en ejecutar una estrategia integral de inclusión y equidad en Medellín, de lucha contra la pobreza e integración de los barrios populares con el resto de la ciudad. La expresión de Luis Alfredo Ramos: "hacíamos unos programitas" en los barrios o que iban a los barrios para "dar la cara" o "transmitir confianza" no son explicaciones satisfactorias para el reto que esto significaba para Medellín en el largo plazo.

El libro se diferencia del resto de literatura sobre el tema del narcotráfico en Medellín por su aporte metodológico y por la consulta de fuentes sobre un tema al que otros tal vez no le habían puesto la lupa. Mucho se habla de los carros-bomba y de los atentados de la época, pero hasta el momento no había leído un texto donde se dijera claramente cuántos fueron, dónde fueron, en qué contexto y qué actores estuvieron implicados. Así que no estamos ante una obra más sobre el narcotráfico en Medellín, sino ante la obra que logró sistematizar y traer de nuevo los hechos que se habían perdido en las hemerotecas de los periódicos. Ese ejercicio periodístico de archivo tiene que ser una prioridad hoy, cuando los hechos del día a día van eclipsando la realidad.

Aristizábal Uribe, Ana Cristina (2018). Medellín a oscuras. Ética antioqueña y narcotráfico. Medellín: Editorial Universidad Pontificia Bolivariana. 253 p. ISBN: 9789587645569.

El libro se puede obtener en: https://www.libreriadelau. com/medellin-a-oscuras-etica-antioquena-y-narcotrafico-upontificia-bolivariana-periodismo/p.

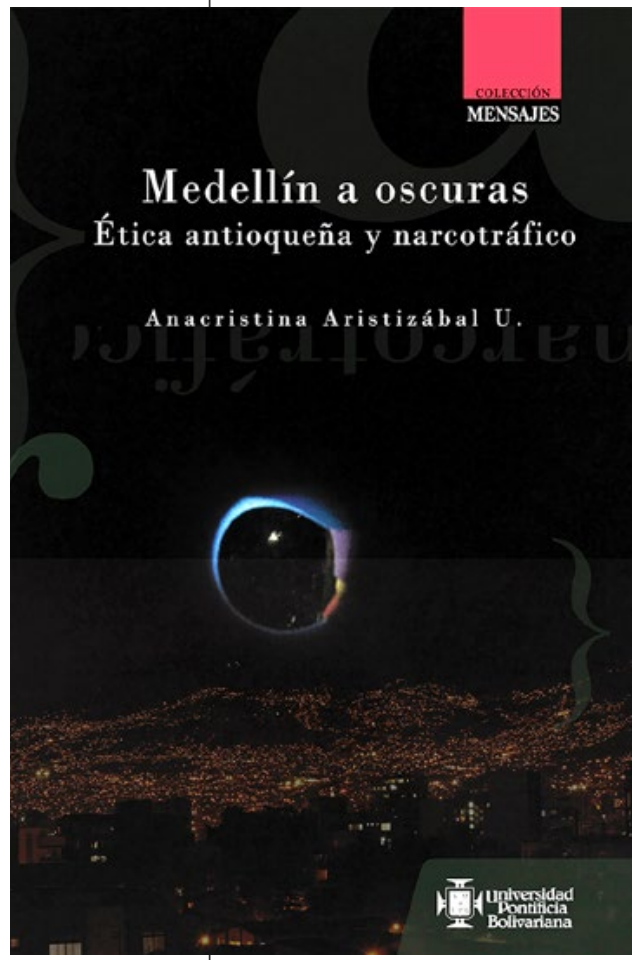




\section{Referencias}

Cardona, G. (2007). La bestia desatada. Bogotá: Editorial Planeta.

Correa, C. \& Mejía, M. (2009). Las llaves del periódico. Medellín: Editorial Universidad EAFIT. Martin, G. (2012). Tragedia y resurrección. Mafia, ciudad y Estado 1975-2012. Bogotá: Editorial Planeta.

Salazar, A. (1990). No nacimos pa' semilla. Medellín: Editorial CINEP. 